\title{
Development of Computational Fluid Dynamics-Habitat Suitability (CFD-HSI) Models To Identify Potential Passage- Challenge Zones for Migratory Fishes in the Penobscot River
}

\begin{abstract}
A two-dimensional computational fluid dynamics-habitat suitability (CFD-HSI) model was developed to identify potential zones of shallow depth and high water velocity that may present passage challenges for five anadromous fish species in the Penobscot River, Maine, upstream from two existing dams and as a result of the proposed future removal of the dams. Potential depth-challenge zones were predicted for larger species at the lowest flow modeled in the dam-removal scenario. Increasing flows under both scenarios increased the number and size of potential velocity-challenge zones, especially for smaller species. This application of the two-dimensional CFD-HSI model demonstrated its capabilities to estimate the potential effects of flow and hydraulic alteration on the passage of migratory fish.
\end{abstract}

More than 100 dams within the Penobscot River watershed provide recreation, flood control, and hydroelectric production, but also restrict the passage of diadromous fishes. The PPL Corporation (owner of several lower mainstem dams), conservation groups, the Penobscot Indian Nation, the State of Maine, and the U.S. Department of the Interior agreed in 2004 to completely remove the two lowermost dams on the Penobscot River main stem (Veazie and Great Works Dams) with primary goals of eliminating migratory obstacles and restoring declining runs in the lower river. Whereas the ability of fish to pass the removed dam structures is expected to improve, the postremoval effects on river hydraulics upstream from the dams are unknown and may create unintended velocity or depth barriers to fish passage in high-gradient or shallow upstream reaches.

Computational fluid dynamics-habitat suitability (CFDHSI) models are commonly developed to determine the suitability of riverine habitat for aquatic organisms on the basis of river-channel depth, velocity, and habitat-related factors. CFD modeling consists of the computation of streamflow velocity, depth, and direction on the basis of hydraulic principles and a known quantity of streamflow; HSI modeling combines the CFD solution of the hydraulic-flow field with the computation of habitat conditions in the river on the basis of species-specific depth and water-velocity criteria.

Two-dimensional (horizontal across- and along-stream dimensions) CFD-HSI models were developed to identify and qualitatively assess potential zones of shallow depth and high water velocity that may present upstream passage challenges for five major anadromous fish species - sea lamprey (Petromyzon marinus), shortnose sturgeon (Acipenser brevirostrum), alewife (Alosa pseudoharengus), American shad (Alosa sapidissima), and Atlantic salmon (Salmo salar) - in a 2.63-km reach of the main stem of the Penobscot River, Maine (fig. 1), as a result of removal of the Great Works Dam downstream of the reach.

This CFD-HSI application sought to identify potential zones of habitat unsuitability, that is, areas in the river channel where water velocity might be too high and (or) water depth too shallow to permit passage of fish (hereafter termed velocity- or depth-challenge zones). These parameters can be easily modeled with CFD-HSI techniques, and zones can be identified if appropriate species-specific depth and water-velocity criteria are known.

Suitability curves were established for each species on the basis of measured distributions of the adult fish body height and length (fig. 2); suitable depths were defined as 1.5 times the mean body heights. Velocity suitability was determined for swimming speeds of 3,5, and 7 body lengths per second (mean body length). These speeds are conservative estimates that range from cruising (sustained) to sprint-like swimming that is likely to be difficult for fish to maintain for long periods.

CFD-HSI was modeled by using River2D (version 0.93, 2006; ${ }^{1}$ University of Alberta, 2010), a two-dimensional depth-

${ }^{1}$ Any use of trade, product, or firm names is for descriptive purposes only and does not imply endorsement by the U.S. Government.

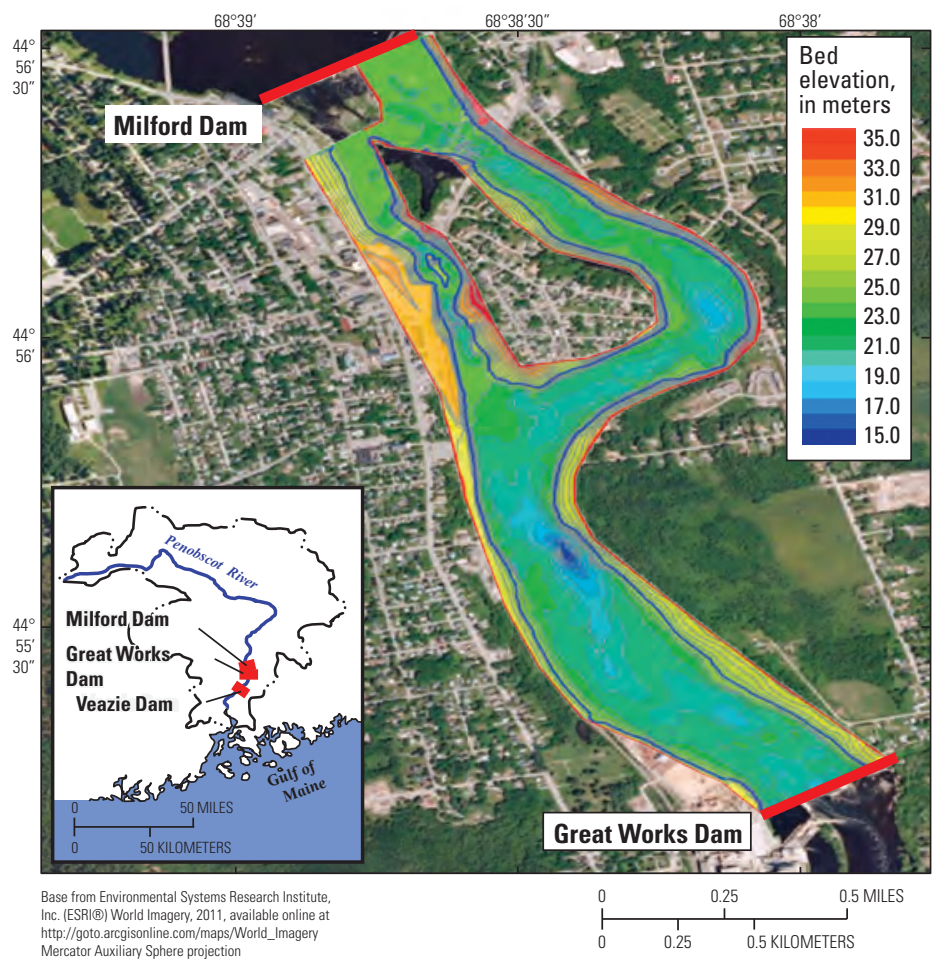

Figure 1. Bathymetry of modeled reach of Penobscot River, central Maine, and the locations of three dams. The Great Works Dam has been proposed for removal. 


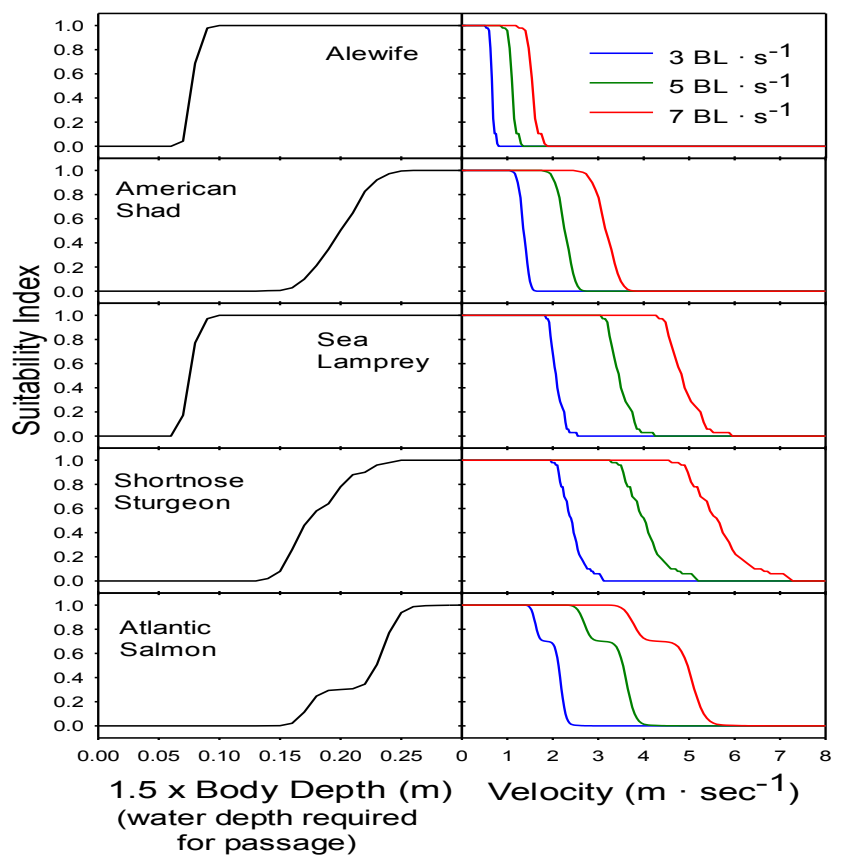

Figure 2. Suitability-index curves for depth (calculated as 1.5 times the vertical body height of the fish) and velocity (calculated as 3, 5, and 7 body lengths per second) criteria for the five target species in the modeled reach of the Penobscot River, southern Maine. Body-size data were taken from specimens collected from the Connecticut River (sea lamprey, American shad), the Town Brook in Plymouth, Massachusetts (alewife), and the Penobscot River (shortnose sturgeon, Atlantic salmon) by the U.S. Geological Survey, the University of Maine, and the National Marine Fisheries Service, respectively. BL/s, body lengths per second.

averaged finite element hydrodynamic model customized for habitat-evaluation studies.

A computational domain for the modeled reach was developed by using multiple topographic and bathymetric datasets and a bed-resistance value of 0.4 meters $(\mathrm{m})$. Three representative simulated streamflows were selected $(99,345$, and 723 meters per second $(\mathrm{m} / \mathrm{s}))$ on the basis of the 25 th-, 50th-, and 75th-percentile flows during the species' spring runs in the Penobscot River (approximately May 1 to July 1). Flow

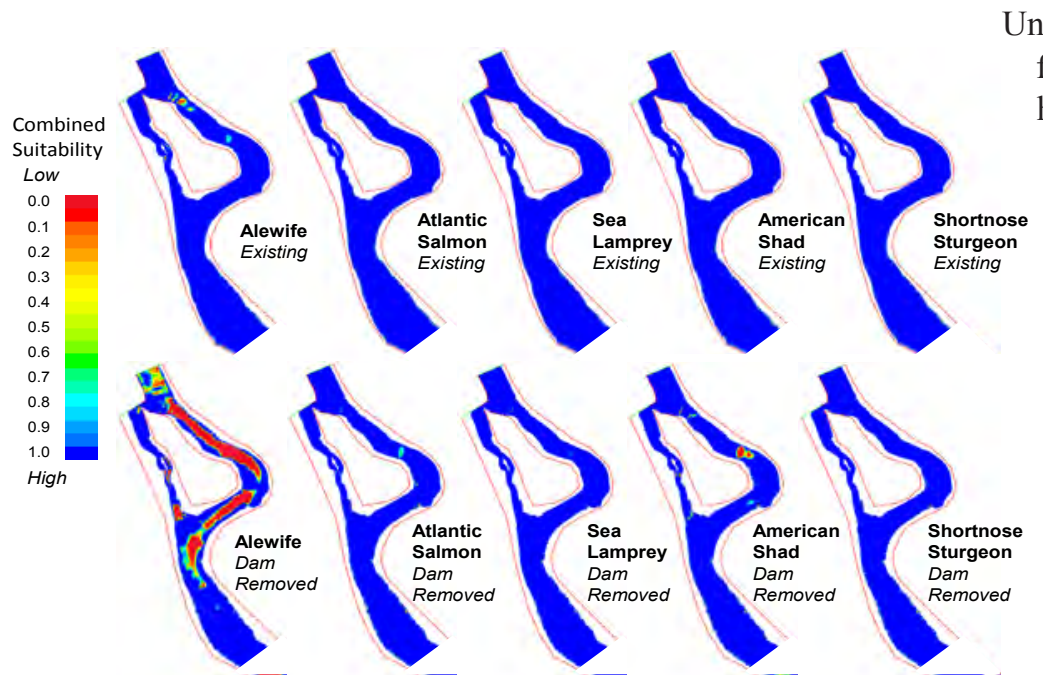

Figure 3. Combined suitability indexes simulated for the five target species at a streamflow of 345 cubic meters per second and a swimming speed of 5 body lengths per second under current (2012) conditions and after removal of the Great Works Dam, Penobscot River, central Maine. and bed-morphology domains were modeled to simulate current (2012) postremoval hydraulic conditions at the downstream boundary of the reach.

Potential depth-challenge zones were classified as contiguous zones within the reach where the depth-suitability index was less than 0.5 and spanned at least 80 percent of the total width of the wetted river channel. Potential velocity-challenge zones were defined as contiguous zones where the velocitysuitability index was less than 0.5 , spanned at least 50 percent of the river channel, and had a contiguous length of at least $10 \mathrm{~m}$ along the main stem of the river.

The simulation indicated potential depth-challenge zones only for the streamflow of $99 \mathrm{~m} / \mathrm{s}$ under the dam-removal scenario for the larger species (sturgeon, shad, and salmon); higher flows in both scenarios increased the number and size of potential velocity-challenge zones, especially for smaller species (fig. 3).

The two-dimensional CFD-HSI model can demonstrate the gross effects of flow and hydraulic alteration, but may not be as precise a predictive tool as a three-dimensional model. In addition, passability of the potential challenge zones cannot be precisely quantified for two- or three-dimensional models because of unvalidated assumptions and incomplete data on fish swimming and other behaviors.

Although the simulated velocity- and depth-challenge zones may be or become physically real, uncertainties about swimming and migratory behaviors preclude precise knowledge as to whether fish can actually pass these zones. More spatially explicit hydraulic modeling (that is, fine-scale, threedimensional modeling of turbulence and eddies) combined with more data describing fish swimming would improve the accuracy of predictions of challenge zones and increase confidence in the ability of fish to negotiate these zones. The two-dimensional CFD-HSI modeling was found to be a useful exploratory tool for identifying potential barriers and the grossscale effects of the alteration of flows, hydrograph, and bed morphology on fish passage.

\section{Reference Cited}

University of Alberta, 2010, River2D hydrodynamic model for fish habitat: University of Alberta, accessed May 25, 2012, at http://www.river2d.ualberta.ca/.

By

Alexander J. Haro, S.O. Conte Anadromous Fish Research Laboratory Robert W. Dudley, USGS Maine Water Science Center Michael Chelminski, Stantec, Inc.

For more information, please contact: Robert Lent, Director U.S. Geological Survey Maine Water Science Center 196 Whitten Road Augusta, ME 04330 Telephone: (207) 622-8201 email: dc_me@usgs.gov 